\title{
Valoração econômica do efeito da erosão em sistemas de manejo do solo empregando o método custo de reposição
}

\author{
Adriane Cristine Vasconcelos Pugliesi ('); Mara de Andrade Marinho (2*); João Fernando Marques (3); \\ José Ricardo Freitas Lucarelli (2) \\ (') Mestranda em Engenharia Agrícola, Área de Concentração de Água e Solo, FEAGRI/ UNICAMP. E-mail: adrianepugliesi@uol.com.br; \\ (2) Faculdade de Engenharia Agrícola, Universidade Estadual de Campinas, 13083-970 Campinas (SP). E-mail: mweill@agr.unicamp.br \\ ${ }^{*}$ ) Autora correspondente: mara.marinho@feagri.unicamp.br \\ (3) Embrapa Meio Ambiente, Caixa Postal 69, 13820-000 Jaguariúna (SP).E-mail: jofemarques@uol.com.br
}

Recebido: 12/set./2008; Aceito: 11/jun./2010

\begin{abstract}
Resumo
A erosão acelerada constitui importante processo de degradação da qualidade das terras agrícolas. Comumente, a perda física de solo é computada, negligenciando-se os efeitos econômicos dessas perdas, que podem ser estimados empregandose métodos de valoração econômica. Este trabalho teve por objetivo aplicar o método Custo de Reposição, para valoração econômica das perdas de nutrientes por erosão de um Latossolo Vermelho Distroférrico típico. Foram analisados dados de perda de solo e de nutrientes provenientes de dois ensaios realizados no município de Campinas (SP). No Ensaio I (19901996) foram testados oito tratamentos, um por parcela, e as repetições ocorreram no tempo. No Ensaio II (2003-2005), foram testados dois tratamentos, com quatro replicações, sendo analisadas duas safras. Para o Ensaio I ocorreram diferenças significativas entre tratamentos para perdas de solos e de nutrientes. O tratamento "plantio direto" foi o que melhor preveniu as perdas por erosão, enquanto que "aração morro abaixo" foi o que mais intensificou esse processo. A intensidade de erosão não teve influência sobre as produtividades de milho, que não se diferenciaram entre tratamentos, assim como também os custos de reposição de nutrientes. Para o Ensaio II, não foram caracterizadas diferenças significativas entre tratamentos para nenhum atributo analisado, podendo ter ocorrido efeito residual do Ensaio I (anterior). O método Custo de Reposição pode ser aplicado como um indicador na avaliação da sustentabilidade de sistemas de manejo do solo. Mas, em ensaios de longa duração, a variação anual dos preços de fertilizantes e de mão-de-obra pode mascarar os efeitos devidos aos tratamentos em si.
\end{abstract}

Palavras-chave: Relação erosão-produtividade, Sistema plantio direto, Perda de solo, Perda de nutrientes por erosão.

\section{Economical valuation of the erosion effect in soil managemnet systems employing the replacement cost method}

\section{Abstract}

The accelerate soil erosion constitutes an important process of agricultural land quality degradation. Often, only the physical soil losses are assessed, neglecting the economical effects of those losses, which could be estimated by applying methods of economical valuation. This work intended to apply the Replacement Cost method to evaluate economically the nutrient losses by erosion from a Rhodic Hapludox. Data concerning soil and nutrient losses were analyzed from two experiments performed in Campinas (SP. In Experiment I (1990-1996), eight treatments were tested, one for each experimental parcel, and the repetitions were the years. In Experiment II (2003-2005), two treatments were tested with four replications, for two growing seasons. In Experiment I, significant differences between treatments occurred in relation to soil and nutrient losses. The "no-tillage" was the best treatment to control the soil erosion losses, whereas the "plowing downhill" was the worst treatment. Apparently, the soil erosion losses didn't affect the corn yields, because differences between treatments were not statistically significant. Also, no significant differences were found between treatments in relation to the costs of nutrient replacement. The differences between treatments of Experiment II were not significant for any analyzed attribute, maybe due to a residual effect from treatments of Experiment I (previous). The Replacement Cost method can be applied as an indicator on the evaluation of the sustainability of soil management systems. However, in long-term experiments, the annual variation of prices of fertilizers and labor could mask the effects of the treatment themselves.

Key words: Erosion-Productivity Relationship, No-tillage system, Soil loss, Nutrients losses by erosion. 


\section{INTRODUÇÃO}

A erosão acelerada do solo constitui importante processo de degradação da qualidade das terras agrícolas (LAL, 1990). No contexto do uso agrícola, os resultados das pesquisas em erosão revelam que as maiores perdas de solo e de água estáo associadas com sistemas de manejo convencionais, que se caracterizam pela aplicação intensiva de mecanizaçáo motorizada, com queima ou incorporação dos restos de culturas e plantio em solo descoberto. Em sentido contrário, as práticas dos sistemas conservacionistas se fundamentam em pequena mobilização mecânica do solo, manejo dos restos culturais com manutenção de cobertura em superfície e rotação de culturas (WANG et at., 2006). Estimativas das perdas de solo por erosão sob diferentes condiçôes de clima e manejo têm sido objeto de pesquisas na área de manejo e conservação do solo, como nos trabalhos de CASTRO et al. (1986), Melo Filho e Silva (I993) e Cassol e Lima (2003). Mormente apenas a quantidade física de terra perdida é avaliada, mas náo os efeitos econômicos resultantes dessas perdas. Assim, a degradação dos recursos naturais não tem sido devidamente valorada, na medida em que os custos advindos dos impactos do uso agrícola nem sempre são computados.

Os métodos de valoraçáo econômica têm o propósito de calcular o valor monetário do recurso natural perdido. No âmbito dos custos privados, os trabalhos de HertzLer et al. (I985), Gardner e Barrows (I985) e King e Sinden (1988) tratam dos efeitos da erosão e da conservação do solo sobre os valores das terras agrícolas. PIEArCe et al. (I984), Kooten et al. (I990) e Xu e Prato (I995) avaliam a relaçáo entre erosão do solo e produtividade do sistema agrícola. Swanson e Maccallum (i969) e Pope et al. (1983) estudaram o impacto da erosão e da conservação do solo sobre a receita e o lucro do agricultor. No Brasil, Kitamura et al. (1982) avaliaram economicamente diferentes sistemas de conservação do solo, enquanto Rodrigues (2005) estimou o valor econômico dos nutrientes perdidos pela erosáo do solo.

Nesse contexto, este trabalho teve por objetivo principal aplicar o método Custo de Reposição na valoração econômica da perda de nutrientes por erosão de um Latossolo Vermelho Distroférrico típico, como subsídio à avaliaçáo da sustentabilidade econômica de diferentes sistemas de manejo do solo.

\section{MATERIAL E MÉTODOS}

O trabalho foi realizado a partir de dados de perdas de solo e de nutrientes provenientes de dois ensaios, Ensaio I (1990-1996) e Ensaio II (2003-2005), realizados no município de Campinas (SP) em área de Latossolo Vermelho Distroférrico típico A moderado relevo ondulado (Rhodic
Hapludox), epieutrófico em função do manejo com calagem e adubaçáo mineral.

As parcelas experimentais, em número de oito, com área de $600 \mathrm{~m}^{2}$ cada uma, ocupam terreno com declividade de $0,09 \mathrm{~m} \mathrm{~m}^{-1}$, exposição oeste e orientação nortesul. Na parte inferior de cada parcela há um sistema coletor construído em alvenaria, constando de uma soleira concentradora e de três tanques com capacidades decrescentes dispostos em sequência, para determinação direta das perdas de solo por erosão.

A pesquisa em erosão nessas parcelas experimentais iniciou-se em 1986, com a remoção do reflorestamento com eucalipto então existente na área. Entre 1986 e 1990 , o preparo do solo das parcelas consistiu de subsolagem a $0,50 \mathrm{~m}$ de profundidade, para remoção de camada compactada, seguida de aração e gradagens de destorroamento e de nivelamento. A cada ano, após o preparo, sucederam-se semeaduras de crotalária (1986/1987), milho (1987/1988), soja (1988/1989) e milho (1989/1990). No ano agrícola 1990/1991, foi implantado o Ensaio I, no qual cada uma das oito parcelas recebeu um sistema de manejo do solo distinto. Os tratamentos do Ensaio I foram os seguintes: T1- Sistema Convencional com Grade Aradora, T2- Sistema Alternado de Equipamentos, T3Sistema Reduzido com Escarificador, T4- Sistema Plantio Direto, T5- Sistema Convencional com Arado de Discos em nível, T6- Parcela Roçada sem Mobilização, T7- Sistema Convencional com Arado de Discos morro abaixo e T8- Sistema de Rotavação.

As parcelas foram cultivadas com milho para pipoca (verão) e apenas na parcela manejada sob sistema plantio direto (T4) foi utilizada aveia preta como planta de cobertura. Anualmente, o solo foi adubado com NPK tomando por base os teores dos nutrientes determinados em uma amostra composta de solo proveniente de amostras simples da camada de $0-20 \mathrm{~cm}$ de todas as parcelas. Por conseguinte, no Ensaio I todas as parcelas experimentais receberam a mesma quantidade de adubo. A cada quatro anos foi efetuada calagem para correção do $\mathrm{pH}$, mantendo-o na faixa de maior disponibilidade de nutrientes, entre 6,0 e 6,5 .

O Ensaio I se estendeu até 2003, mas no presente trabalho foram analisados somente os dados relativos às safras: 1990/1991, 1991/1992, 1992/1993, 1993/1994, 1994/1995, 1995/1996. Foram analisados dados de produtividade anual de milho para pipoca (em kg ha-1), de perdas totais de solo por erosão (em kg $\left.{ }^{-1} \mathrm{ha}^{-1} \mathrm{safra}^{-1}\right)$ e de teores dos macronutrientes cálcio $(\mathrm{Ca})$, magnésio $(\mathrm{Mg})$, potássio $(\mathrm{K})$ e fósforo $(\mathrm{P})$ e de matéria orgânica, determinados a partir da análise química de uma amostra composta do material erodido por tratamento por safra. Para estimativa do teor total de nutriente perdido, a concentraçáo do mesmo, determinada pela análise química, foi multiplicada pela perda total de terra por tratamento por safra. 
Em 2003, foi instalado o Ensaio II nas mesmas oito parcelas experimentais. Foram testados dois tratamentos, Sistema Plantio Direto (SD) e Sistema Convencional com grade aradora em nível (PC), em um delineamento experimental casualizado com quatro replicaçôes (quatro parcelas por tratamento). $\mathrm{Na}$ locaçáo dos tratamentos, a definição das parcelas de cada tratamento foi definida por sorteio, impondo-se que as quatro replicaçóes de cada tratamento ficassem em sequência, para otimizar o rendimento da semeadora e se aproximar mais da condição do trabalho mecânico em uma lavoura comercial.

Anteriormente à instalação do Ensaio II, foi realizada escarificação em área total a $30 \mathrm{~cm}$ de profundidade visando à homogeneização do solo das parcelas. Então, em agosto de 2003 foi semeada aveia preta, cujas plantas foram posteriormente dessecadas, trituradas e mantidas como cobertura no solo nas parcelas sob SD e incorporadas nas parcelas sob PC. Em novembro de 2003, em todas as parcelas fez-se a semeadura de milho para grão, variedade SHS 4050 da Santa Helena Sementes, com densidade de plantio equivalente a 50 mil plantas por hectare. Por ocasião da semeadura, fez-se adubação NPK, diferenciando-se a quantidade aplicada de adubo em cada parcela, de acordo com os resultados da análise de fertilidade do solo realizada para cada parcela. A adubaçáo nitrogenada foi parcelada, fazendo-se adubação de cobertura aos 45 dias da cultura. Na safra seguinte (2004/05), foram mantidos os mesmos procedimentos, e a semeadura do milho ocorreu em dezembro de 2004.

Foram analisados os dados de produtividade anual de milho (em kg ha-1) e as perdas de solo e de nutrientes por erosão (em kg ${ }^{-1} \mathrm{ha}^{-1} \mathrm{safra}^{-1}$ ) por tratamento e por safra. Para determinação direta das perdas de solo por erosão, foi realizada coleta mensal dos sedimentos aos 30, 60, 90 e 120 dias após o plantio, de acordo com método descrito por Mucthler et al. (1994). Na safra de 2003/2004, foi necessário realizar uma coleta intermediária do material erodido após a semeadura, devido à ocorrência de elevada precipitação pluvial no período. De cada coleta mensal do material erodido, foi retirada uma amostra para determinação dos teores de macronutrientes $(\mathrm{Ca}$, $\mathrm{Mg}, \mathrm{K}$ e P) e de matéria orgânica. As estimativas dos teores de nitrogênio $(\mathrm{N})$ foram feitas indiretamente, com base nos teores de matéria orgânica, considerando que um grama de matéria orgânica contém cerca de 5\% de nitrogênio (Tomé Júnior., 1997). Com base nos resultados das análises, multiplicando a concentração de um dado nutriente pelo total de terra perdida em determinada coleta, obteve-se o teor perdido do respectivo nutriente naquela coleta. $\mathrm{O}$ somatório dos teores perdidos em todas as coletas de um tratamento e uma safra forneceu a perda total do referido nutriente $\left(\mathrm{kg} \mathrm{ha}^{-1}\right)$ para aquele tratamento e para aquela safra. Este procedimento foi realizado para cada nutriente.

Nos dois ensaios, a valoração econômica da degradação do solo por erosão foi realizada empregando o método denominado "Custo de Reposição" (Hufschmidt et al. i983; Dixon e Hufschmidt, 1986). Foram estimados os custos relativos exclusivamente às perdas de nutrientes por erosão ocorridas durante o período da safra de milho (120 dias ao ano), utilizando a equação 1 , extraída de Marques (1998):

$\mathrm{C} I=(\mathrm{Qn} * \mathrm{Pn})+\mathrm{Ca}$

Sendo: $\mathrm{CI}=$ custo de reposição de nutrientes, expresso em $\mathrm{R} \$ \mathrm{ha}^{-1}$ safra $^{-1}$;

$\mathrm{Qn}=$ fertilizantes carreados pela erosão, em $\mathrm{kg} \mathrm{ha}^{-1}$ safra $^{-1}$;

Pn $=$ preço dos fertilizantes, em reais $\mathrm{R} \$ \mathrm{~kg}^{-1}$;

$\mathrm{Ca}=$ custo de aplicação dos fertilizantes, em reais $\mathrm{R} \$$ ha $^{-1}$ safra $^{-1}$.

Para fins de cálculo dos custos de reposição dos nutrientes, foram determinadas as quantidades equivalentes de adubos correspondentes às perdas totais de cada nutriente por erosáo por tratamento por safra para os Ensaios I e II. Foram considerados os seguintes adubos: uréia $(45 \% \mathrm{~N})$, superfosfato simples $\left(18 \% \mathrm{P}_{2} 0_{5}\right)$, cloreto de potássio $\left(58 \% \mathrm{~K}_{2} \mathrm{O}\right)$ e calcário dolomítico $(25 \% \mathrm{CaO}$ $+13 \% \mathrm{MgO}$ ). Os preços médios dos fertilizantes ( $\mathrm{Pn}$, em $\left.\mathrm{R} \$ \mathrm{~kg}^{-1}\right)$ foram calculados com a atualização monetária dos valores da série histórica de preços cedida pelo Instituto de Economia Agrícola (IEA). Os valores foram convertidos para R\$ (real) e depois deflacionados pelo índice IGPDI, tomando por data base Dez./2005=100. Em seguida, os valores em Reais de Dez./2005, foram corrigidos pelo índice 2, de Conjuntura Econômica, Disponibilidade Interna, da Fundação Getúlio Vargas ${ }^{(6)}$. O custo de aplicação de fertilizantes $\left(\mathrm{Ca}\right.$, em $\left.\mathrm{R} \$ \mathrm{ha}^{-1}\right)$ foi estimado considerando que a adubaçáo de um hectare de milho requer um trabalhador despendendo 12 horas ou uma diária e meia. Considerando que foram realizadas duas adubaçôes da cultura de milho (na semeadura e em cobertura), o custo de aplicação de fertilizantes foi computado como de três diárias por hectare. Os valores correntes e corrigidos da mão-obra "diarista" para o Estado de São Paulo foram fornecidos pelo IEA $^{(7)}$, utilizando-se o valor da média anual da diária no Estado para o trabalhador do campo.

Os resultados foram submetidos à análise exploratória, com verificação da normalidade dos dados pelo teste de Shapiro-Wilk. A hipótese de homogeneidade de

${ }^{\left({ }^{6}\right)}$ Variação dos preços médios por Megagrama de corretivo ou fertilizantes, base em reais de 2005: Calcário Dolomítico: de R\$33,00 (2005) a R\$76,60 (1990); Cloreto de potássio: de $R \$ 777,00$ a $R \$ 1.195,00 ;$ Superfostato Simples: de $R \$ 446,00$ a $R \$ 717,00 ;$ Uréia: de $R \$ 977,20$ a $R \$ 1.378,00$.

( $\left.{ }^{7}\right)$ Custo de mão-de-obra diária em reais de 2005, de acordo com a Tabela DI do Anexo D (IEA - correção IGP - DI): 1990- R\$10,48; 1991- R\$12,67; 1992-R\$9,98; 1993$\mathrm{R} \$ 11,08 ; 1994-\mathrm{R} \$ 10,32 ; 1995-\mathrm{R} \$ 14,60 ; 1996-\mathrm{R} \$ 21,39 ; 2003-\mathrm{R} \$ 17,13 ; 2004-\mathrm{R} \$ 15,80 ; 2005-\mathrm{R} \$ 17,43$. 
variância dos erros amostrais foi testada aplicando o teste da razão máxima de Hartley (RAmalho et al., 2000), cujos valores foram comparados com os valores tabelados em nível de $1 \%$ de probabilidade. A análise de variância foi realizada considerando dois sistemas de dados foram analisados empregando o teste $\mathrm{F}$, com comparação de médias pelo teste de manejo (tratamentos) com quatro replicações cada uma (oito parcelas experimentais). Os Tukey $(\mathrm{p}>0,05)$, utilizando o programa computacional SAS.

\section{RESULTADOS E DISCUSSÃO}

Os resultados das análises demonstraram a ocorrência de normalidade e de homogeneidade de variância para todo o conjunto de dados e para todos os atributos avaliados na pesquisa.

A tabela 1 resume as estatísticas descritivas da perda de solo por tratamento para seis safras do Ensaio I (19901996). Pelos resultados observam-se diferenças significativas entre tratamentos para perda de solo, e as menores perdas, inferiores a $122 \mathrm{~kg} \mathrm{ha}^{-1}$, ocorreram na parcela mantida com gramínea e apenas roçada (T6) e na parcela manejada sob sistema plantio direto (T4), que não se diferenciaram entre si. A maior perda de solo $\left(4.677,89 \mathrm{~kg} \mathrm{ha}^{-1}\right)$ ocorreu na parcela manejada sob aração morro abaixo (T7), diferenciando-se significativamente do segundo maior valor $\left(1.475,85 \mathrm{~kg} \mathrm{ha}^{-1}\right)$ ocorrido na parcela manejada sob rotavação (T8). As perdas de solo das parcelas manejadas com grade aradora (T1), sistema alternado (T2), escarificação
(T3) e aração em nível (T5) não se diferenciaram entre si, com perdas variando entre $526,00 \mathrm{~kg} \mathrm{ha}^{-1}$ e $623,45 \mathrm{~kg}$ $\mathrm{ha}^{-1}$. Desconsiderando a parcela mantida roçada, o tratamento T4 plantio direto foi o de menor perda média de solo enquanto $\mathrm{T} 7$ aração morro abaixo foi o de maior valor. CASTRO et al. (1986) já haviam demonstrado que os sistemas convencionais de preparo do solo, em especial em áreas de produção de culturas anuais, intensificam o processo erosivo. Os resultados reafirmam a manutenção da cobertura do solo e o plantio em nível como práticas essenciais de controle da erosão em áreas agrícolas.

Resultados semelhantes foram observados no Ensaio II, evidenciando valores médios elevados de perda de solo por erosão para o tratamento convencional com grade aradora em nível (PC) em relação aos registrados para o tratamento conservacionista com plantio direto (SD) (Tabela 2). ELtz et al. (2001) também constataram grandes diferenças nas taxas de perda de solo oriundas de sistemas convencionais e conservacionistas.

A tabela 3 ilustra as estatísticas descritivas da produtividade de milho para pipoca por tratamento do Ensaio I (1990 a 1996). Os valores médios de produtividade variaram entre $1.400,00 \mathrm{~kg} \mathrm{ha}^{-1} \mathrm{e} 2.200,00 \mathrm{~kg}$ $\mathrm{ha}^{-1}$, não tendo sido caracterizadas, no entanto, diferenças estatisticamente significativas entre tratamentos. Tais resultados indicam que a produtividade do milho para pipoca náo foi afetada pela erosão, a despeito da grande diferenciação entre tratamentos do Ensaio I quanto às perdas de solo. De acordo com Pierce e LaL (1994), a dificuldade em relacionar diretamente erosão e produtividade reside no fato de que a resposta das

Tabela 1. Estatísticas descritivas da perda de solo por erosáo, por tratamento do Ensaio I (1990 a 1996)

\begin{tabular}{|c|c|c|c|c|c|c|}
\hline \multirow{2}{*}{ Tratamento } & \multirow{2}{*}{ Descrição } & Média & s & Mínimo & Máximo & C.V. \\
\hline & & \multicolumn{4}{|c|}{$\mathbf{k g ~ h a}^{-1}$} & $\%$ \\
\hline T1 & Grade aradora & $623,45 \mathrm{C}$ & 58,36 & 543,04 & 714,55 & 9,36 \\
\hline $\mathrm{T} 2$ & Sistema alternado & $585,34 \mathrm{C}$ & 24,63 & 556,35 & 625,45 & 4,21 \\
\hline T3 & Escarificação & $525,67 \mathrm{C}$ & 68,37 & 417,04 & 600,35 & 13,01 \\
\hline T4 & Plantio direto & $121,36 \mathrm{D}$ & 21,14 & 100,45 & 154,58 & 17,42 \\
\hline T5 & Aração em nível & $606,89 \mathrm{C}$ & 64,00 & 508,56 & 677,57 & 10,55 \\
\hline T6 & Roçado & $73,23 \mathrm{D}$ & 4,15 & 69,45 & 81,25 & 5,67 \\
\hline T7 & Aração morro abaixo & $4.677,89 \mathrm{~A}$ & 472,96 & $4.256,88$ & $5.506,25$ & 10,11 \\
\hline T8 & Rotavação & $1.475,85 \mathrm{~B}$ & 223,15 & $1.256,89$ & $1.859,45$ & 15,12 \\
\hline
\end{tabular}

Valores médios (seis safras) seguidos de mesma letra maiúscula năo diferem estatisticamente entre si pelo teste de Tukey (p>0,05). s: desvio-padrão. C.V.: coeficiente de variaçăo.

Tabela 2. Estatísticas descritivas das perdas anuais de solo por erosão nas parcelas experimentais para as duas safras iniciais do Ensaio II (2003 a 2005)

\begin{tabular}{|c|c|c|c|c|c|}
\hline \multicolumn{6}{|c|}{ Safra 2003/04 } \\
\hline \multirow{2}{*}{ Tratamento } & Média & Mínimo & Máximo & s & C.V. \\
\hline & \multicolumn{4}{|c|}{$\mathrm{kg} \mathrm{ha}^{-1}$} & $\%$ \\
\hline SD & $379,80 \mathrm{~A}$ & 206,21 & 548,88 & 162,53 & 42,79 \\
\hline PC & $2.098,45 \mathrm{~A}$ & 246,00 & $4.642,92$ & $1.993,30$ & 94,99 \\
\hline \multicolumn{6}{|c|}{ Safra 2004/05 } \\
\hline SD & $309,35 \mathrm{~A}$ & 144,80 & 475,23 & 137,15 & 44,34 \\
\hline PC & $4.354,27 \mathrm{~A}$ & 628,85 & $11.732,24$ & $5.532,37$ & 120,17 \\
\hline
\end{tabular}

Valores médios seguidos de mesma letra maiúscula năo diferem entre si pelo teste de Tukey (p>0,05). s: desvio-padrăo. C.V.: coeficiente de variaçăo. Tratamentos: SD: sistema plantio direto. PC: sistema convencional com grade aradora. 
plantas à erosão é complexa e envolve a avaliação de uma série de interaçóes entre a cultura e os atributos do solo, da paisagem, do clima predominante e do nível de manejo e de aplicaçáo de insumos.

As estatísticas descritivas da produtividade de milho do Ensaio II (2003 a 2005) constam da tabela 4, e de modo similar ao obtido para o Ensaio I não foi possivel estabelecer uma relação direta entre perda de solo e produtividade de milho. Com relação à safra 2003/2004, destaca-se que a produtividade mínima do tratamento conservacionista (SD), de $8.070,60 \mathrm{~kg} \mathrm{ha}^{-1}$, foi muito similar à produtividade máxima do tratamento convencional (PC), de 8.157,46 kg ha-1; ainda, observa-se que a produtividade máxima dessa safra ocorreu no tratamento (SD), na parcela também manejada sob plantio direto no Ensaio I. Para a safra de 2004/2005, os valores médios de produtividade foram inferiores aos da safra anterior para os dois tratamentos, mas com queda muito mais acentuada para o tratamento conservacionista (SD). Com base nos fatores analisados neste trabalho, não é possível explicar essa ocorrência. A produtividade máxima, de 8.882,41 $\mathrm{kg} \mathrm{ha}{ }^{-1}$, ocorreu em uma parcela do tratamento convencional (PC), que no Ensaio I foi manejada com aração em nível.

A tabela 5 relaciona os teores totais de nutrientes perdidos por erosão no período entre 1990 e 1996 para oito tratamentos do Ensaio I. Na mesma tabela constam as estatísticas descritivas e os resultados dos testes de médias entre tratamentos. As perdas de nitrogênio $(\mathrm{N})$ foram significativamente maiores nos tratamentos $\mathrm{T} 7$ - aração morro abaixo e T8 - rotavação, e não se diferenciaram nos demais. Para o fósforo $(\mathrm{P})$, as menores perdas ocorreram para os tratamentos T4 - plantio direto, T6- roçado e T8 - rotavação, que não se diferenciaram entre si. $\mathrm{O}$ tratamento T7 - araçáo morro abaixo se diferenciou de todos os demais, detendo as maiores perdas de fósforo. No caso do potássio $(\mathrm{K})$, os tratamentos T4 e T6 não se diferenciaram entre si, mas tiveram perdas significativamente menores do que T1 - grade aradora, T7 e T8. Quanto ao magnésio $(\mathrm{Mg})$, os tratamentos $\mathrm{T} 2$ - sistema alternado, T3 - escarificaçáo, T4- plantio direto e T6- roçado não de diferenciaram entre si, mas tiveram perdas significativamente menores de $\mathrm{Mg}$ do que a ocorrida no tratamento T7 - aração morro abaixo. Para o cálcio $(\mathrm{Ca})$, as maiores perdas ocorreram no tratamento $\mathrm{T} 7$, que se diferenciou de todos os demais. Os tratamentos T6 - roçado e T5 - aração em nível se diferenciaram entre si, sendo as perdas de T6 significativamente menores do que as de T5. De modo geral, maiores perdas de nutrientes ocorreram nos tratamentos convencionais de manejo do solo, de modo similar ao relatado por Blevins e FrYe (1993), que também observaram menores perdas de nutrientes em sistemas conservacionistas quando comparados com sistemas convencionais.

Com relação ao Ensaio II (2003-2005), os resultados da análise de variância e dos testes de médias (Tabela 6) evidenciam que as diferenças observadas entre tratamentos com relaçáo aos teores de nutrientes perdidos do solo por erosão não são significativas para as duas safras analisadas.

A estimativa dos custos de reposição de nutrientes perdidos do solo por erosão para os tratamentos do Ensaio I (1990-1996) está relacionada na tabela 7. Como

Tabela 3. Estatísticas descritivas da produtividade de milho para pipoca por tratamento do Ensaio I (1990-1996)

\begin{tabular}{|c|c|c|c|c|c|c|}
\hline \multirow{2}{*}{ Tratamento } & \multirow{2}{*}{ Descrição } & Média & s & Mínimo & Máximo & C.v. \\
\hline & & \multicolumn{4}{|c|}{ kg ha-1 } & $\%$ \\
\hline T1 & Grade aradora & $2.166,99 \mathrm{~A}$ & $1.136,72$ & $1.250,00$ & $3.750,00$ & 52,46 \\
\hline $\mathrm{T} 2$ & Sistema alternado & $1.917,96 \mathrm{~A}$ & $1.055,36$ & 947,33 & $3.450,00$ & 55,02 \\
\hline T3 & Escarificação & $1.542,86 \mathrm{~A}$ & 989,72 & 614,00 & $2.826,51$ & 64,15 \\
\hline T4 & Plantio direto & $1.725,30 \mathrm{~A}$ & 695,56 & $1.000,17$ & $2.884,99$ & 40,32 \\
\hline T5 & Aração em nível & $1.689,75 \mathrm{~A}$ & $1.132,09$ & 891,00 & $3.430,80$ & 67,00 \\
\hline T6 & Roçado & - & - & - & - & - \\
\hline T7 & Aração morro abaixo & $1.586,28 \mathrm{~A}$ & 759,97 & 703,33 & $2.616,67$ & 47,91 \\
\hline T8 & Rotavação & $1.400,23 \mathrm{~A}$ & 677,47 & 621,00 & $2.283,33$ & 48,38 \\
\hline
\end{tabular}

Valores médios seguidos de mesma letra maiúscula não diferem estatisticamente entre si pelo teste de Tukey (p>0,05). s: desvio-padrăo. C.V.: coeficiente de variaçăo.

Tabela 4. Estatísticas descritivas da produtividade de milho para grão (Variedade SHS 4050) por tratamento para as duas safras iniciais do Ensaio II (2003 a 2005)

\begin{tabular}{|c|c|c|c|c|c|}
\hline \multicolumn{6}{|c|}{ Safra 2003/04 } \\
\hline \multirow{2}{*}{ Tratamento } & Média & 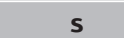 & Mínimo & Máximo & C.V. \\
\hline & & \multicolumn{2}{|c|}{$\mathrm{kg} \mathrm{ha}^{-1}$} & \multicolumn{2}{|c|}{$\%$} \\
\hline SD & $8.915,31 \mathrm{~A}$ & $1.362,43$ & $8.070,60$ & $10.941,12$ & 15,28 \\
\hline PC & $7.832,27 \mathrm{~A}$ & 258,67 & $7.546,66$ & $8.157,46$ & 3,30 \\
\hline \multicolumn{6}{|c|}{ Safra 2004/05 } \\
\hline SD & $7.124,63 \mathrm{~A}$ & 299,81 & $6.729,23$ & $7.442,60$ & 4,21 \\
\hline PC & $7.180,37 \mathrm{~A}$ & $1.275,07$ & $5.999,84$ & $8.882,41$ & 17,76 \\
\hline
\end{tabular}

Valores médios seguidos de mesma letra maiúscula nāo diferem entre si pelo teste de Tukey (p>0,05). s: desvio-padrão. C.V.: coeficiente de variaçấo. Tratamentos: SD: sistema plantio direto. PC: sistema convencional com grade aradora. 
esperado, os custos de reposição de nutrientes aumentaram com o incremento da quantidade de solo perdida. $\mathrm{O}$ menor custo médio de reposição de nutrientes foi estimado em 41,40 R \$ ha ${ }^{-1}$ para o tratamento T4- plantio direto, representando cerca de $65 \%$ do maior valor médio estimado de 63,92 R \$ ha ${ }^{-1}$ para o tratamento T7- aração morro abaixo. As diferenças entre tratamentos do Ensaio I, no entanto, não são significativas, presumindo-se que

Tabela 5. Teores totais no período (1990-1996), ícones médios entre safras e estatísticas descritivas dos teores anuais de nutrientes perdidos do solo por erosáo para oito tratamentos do Ensaio I

\begin{tabular}{|c|c|c|c|c|c|c|}
\hline \multirow{2}{*}{ Nutriente } & & Média & Min & Max & Desvio-padrão & C.V. \\
\hline & & \multicolumn{4}{|c|}{ kg ha $^{-1}$ safra $^{-1}$} & $\%$ \\
\hline \multicolumn{7}{|c|}{ T1 - Grade Aradora } \\
\hline Nitrogênio & 9,39 & $1,57 \mathrm{C}$ & 1,25 & 1,81 & 0,23 & 14,41 \\
\hline Fósforo & 0,39 & $0,06 \mathrm{AB}$ & 0,04 & 0,09 & 0,02 & 33,49 \\
\hline Potássio & 0,68 & $0,11 \mathrm{~B}$ & 0,07 & 0,15 & 0,03 & 24,26 \\
\hline Magnésio & 2,82 & $0,47 \mathrm{AB}$ & 0,14 & 1,27 & 0,44 & 93,81 \\
\hline Cálcio & 12,16 & $2,03 \mathrm{BC}$ & 1,43 & 3,81 & 0,92 & 45,49 \\
\hline \multicolumn{7}{|c|}{ T2 - Sistema Alternado } \\
\hline Nitrogênio & 7,61 & $1,27 \mathrm{C}$ & 1,17 & 1,53 & 0,14 & 10,78 \\
\hline Fósforo & 0,34 & $0,06 \mathrm{ABC}$ & 0,04 & 0,07 & 0,01 & 20,69 \\
\hline Potássio & 0,61 & $0,10 \mathrm{BC}$ & 0,06 & 0,14 & 0,03 & 30,95 \\
\hline Magnésio & 2,52 & $0,42 \mathrm{~B}$ & 0,11 & 0,85 & 0,36 & 84,93 \\
\hline Cálcio & 10,46 & $1,74 \mathrm{BC}$ & 1,10 & 2,62 & 0,65 & 37,14 \\
\hline \multicolumn{7}{|c|}{ T3 - Escarificação } \\
\hline Nitrogênio & 7,69 & $1,28 \mathrm{C}$ & 0,90 & 1,72 & 0,28 & 21,66 \\
\hline Fósforo & 0,26 & $0,04 \mathrm{BC}$ & 0,03 & 0,06 & 0,02 & 35,90 \\
\hline Potássio & 0,59 & $0,10 \mathrm{BC}$ & 0,05 & 0,17 & 0,04 & 41,92 \\
\hline Magnésio & 1,79 & $0,30 \mathrm{~B}$ & 0,10 & 0,59 & 0,19 & 64,09 \\
\hline Cálcio & 9,80 & $1,63 \mathrm{BC}$ & 1,15 & 2,29 & 0,40 & 24,59 \\
\hline \multicolumn{7}{|c|}{ T4 - Plantio Direto } \\
\hline Nitrogênio & 2,37 & $0,39 \mathrm{C}$ & 0,21 & 0,58 & 0,12 & 30,68 \\
\hline Fósforo & 0,09 & $0,02 \mathrm{D}$ & 0,01 & 0,03 & 0,01 & 63,69 \\
\hline Potássio & 0,15 & $0,03 \mathrm{CD}$ & 0,01 & 0,04 & 0,01 & 34,58 \\
\hline Magnésio & 1,15 & $0,19 \mathrm{~B}$ & 0,03 & 0,65 & 0,25 & 129,29 \\
\hline Cálcio & 3,98 & $0,66 \mathrm{BC}$ & 0,32 & 1,60 & 0,52 & 79,18 \\
\hline \multicolumn{7}{|c|}{ T5 - Aração em Nível } \\
\hline Nitrogênio & 8,41 & $1,40 \mathrm{C}$ & 1,07 & 2,17 & 0,42 & 30,21 \\
\hline Fósforo & 0,27 & $0,05 \mathrm{BC}$ & 0,03 & 0,07 & 0,01 & 31,80 \\
\hline Potássio & 0,50 & $0,08 \mathrm{BCD}$ & 0,04 & 0,16 & 0,04 & 46,33 \\
\hline Magnésio & 4,53 & $0,76 \mathrm{AB}$ & 0,09 & 2,03 & 0,85 & 112,09 \\
\hline Cálcio & 17,32 & $2,89 \mathrm{~B}$ & 1,04 & 7,89 & 2,67 & 92,56 \\
\hline \multicolumn{7}{|c|}{ T6 - Roçado } \\
\hline Nitrogênio & 1,55 & $0,26 \mathrm{C}$ & 0,22 & 0,33 & 0,04 & 14,80 \\
\hline Fósforo & 0,04 & $0,01 \mathrm{D}$ & 0,00 & 0,01 & 0,00 & 40,12 \\
\hline Potássio & 0,09 & $0,01 \mathrm{D}$ & 0,01 & 0,02 & 0,00 & 19,77 \\
\hline Magnésio & 1,28 & $0,21 \mathrm{~B}$ & 0,02 & 0,79 & 0,30 & 139,15 \\
\hline Cálcio & 2,92 & $0,49 \mathrm{C}$ & 0,16 & 1,45 & 0,51 & 104,2 \\
\hline \multicolumn{7}{|c|}{ T7 - Aração Morro Abaixo } \\
\hline Nitrogênio & 44,26 & $7,38 \mathrm{~A}$ & 3,63 & 9,64 & 2,08 & 28,24 \\
\hline Fósforo & 0,44 & $0,07 \mathrm{~A}$ & 0,06 & 0,10 & 0,01 & 18,13 \\
\hline Potássio & 2,14 & $0,36 \mathrm{~A}$ & 0,20 & 0,45 & 0,10 & 28,50 \\
\hline Magnésio & 8,33 & $1,39 \mathrm{~A}$ & 0,58 & 2,37 & 0,86 & 61,81 \\
\hline Cálcio & 33,61 & $5,60 \mathrm{~A}$ & 3,50 & 7,55 & 1,63 & 29,09 \\
\hline \multicolumn{7}{|c|}{ T8 - Rotavação } \\
\hline Nitrogênio & 27,41 & $4,57 \mathrm{~B}$ & 1,89 & 8,45 & 2,14 & 46,76 \\
\hline Fósforo & 0,20 & $0,03 \mathrm{CD}$ & 0,02 & 0,04 & 0,01 & 23,84 \\
\hline Potássio & 0,70 & $0,12 \mathrm{~B}$ & 0,08 & 0,15 & 0,03 & 24,89 \\
\hline Magnésio & 2,64 & $0,44 \mathrm{AB}$ & 0,15 & 0,79 & 0,29 & 65,57 \\
\hline Cálcio & 15,06 & $2,51 \mathrm{BC}$ & 1,59 & 2,94 & 0,51 & 20,25 \\
\hline
\end{tabular}

Para um mesmo nutriente, valores médios em diferentes tratamentos seguidos de mesma letra maiúscula não diferem estatisticamente entre si pelo teste de Tukey (p $>0,05$ ). 
o efeito da variação anual relativamente alta dos custos dos fertilizantes e corretivos e da mão-de-obra (vide valores nas notas de rodape 6 e 7) pode ter contribuído para mascarar os efeitos dos tratamentos em si, o que evidenciaria um viés desse método de valoração.

Os resultados da estimativa dos custos de reposiçáo de nutrientes para os tratamentos do Ensaio II constam da tabela 8. Na composição dos custos de reposição, para o sistema plantio direto, o preço dos nutrientes representou em média cerca de apenas $20 \%$ do valor total, enquanto o preço da mão-de obra representou em média os $80 \%$ restantes. Para o sistema convencional, os preços de fertilizantes e de mão-de-obra representaram cerca de $50 \%$ cada um na composiçáo do custo de reposiçáo final. Como o valor da mão-de-obra foi o mesmo para os dois sistemas de manejo, depreende-se ter ocorrido perda muito menor de nutrientes a partir do sistema plantio direto. O custo médio de reposição de nutrientes perdidos do solo por erosão para duas safras nas parcelas sob sistema plantio direto (SD) variou em torno de $62,00 \mathrm{R} \$ \mathrm{ha}^{-1}$.

Nas parcelas manejadas sob sistema convencional (PC), o custo médio para duas safras ficou em torno de $148,00 \mathrm{R} \$$ ha $^{-1}$, representando custos maiores em cerca de $42 \%$ em relaçáo ao manejo sob sistema plantio direto. A esse respeito, Rodrigues (2005) relata uma redução em

Tabela 6. Estatísticas descritivas dos teores de nutrientes perdidos do solo por erosão para dois tratamentos do Ensaio II (2003-2005)

\begin{tabular}{|c|c|c|c|c|c|c|c|c|c|c|}
\hline \multicolumn{6}{|c|}{ SPD } & \multicolumn{5}{|c|}{ PC } \\
\hline \multirow{2}{*}{ Nutriente } & Média & Min & Max & s & CV & Média & Min & Max & s & CV \\
\hline & \multicolumn{3}{|c|}{ kg ha ${ }^{-1}$ safra $^{-1}$} & \multicolumn{3}{|c|}{$\%$} & \multicolumn{2}{|c|}{$k_{g}$ ha $^{-1}$ safra $^{-1}$} & & $\%$ \\
\hline Nitrogêncio & $3,38 \mathrm{~A}$ & 1,53 & 5,38 & 1,85 & 54,67 & $23,78 \mathrm{~B}$ & 2,52 & 54,30 & 23,37 & 98,29 \\
\hline Fósforo & $0,10 \mathrm{~A}$ & 0,04 & 0,16 & 0,06 & 62,88 & $0,25 \mathrm{~A}$ & 0,08 & 0,45 & 0,15 & 61,01 \\
\hline Potássio & $0,20 \mathrm{~A}$ & 0,09 & 0,30 & 0,10 & 52,19 & $0,93 \mathrm{~A}$ & 0,11 & 2,03 & 0,86 & 91,98 \\
\hline Magnésio & $0,27 \mathrm{~A}$ & 0,12 & 0,41 & 0,16 & 57,93 & $1,85 \mathrm{~A}$ & 0,20 & 4,29 & 1,82 & 98,67 \\
\hline Cálcio & $2,74 \mathrm{~A}$ & 1,60 & 4,23 & 1,52 & 55,32 & $15,77 \mathrm{~A}$ & 1,66 & 33,87 & 14,60 & 92,61 \\
\hline \multicolumn{11}{|c|}{ Safra 2004/05 } \\
\hline Nitrogêncio & $2,43 \mathrm{~A}$ & 1,08 & 3,92 & 1,17 & 48,17 & $35,93 \mathrm{~B}$ & 4,99 & 94,84 & 42,26 & 117,62 \\
\hline Fósforo & $0,08 \mathrm{~A}$ & 0,02 & 0,20 & 0,08 & 97,16 & $0,49 \mathrm{~A}$ & 0,14 & 1,29 & 0,54 & 110,22 \\
\hline Potássio & $0,18 \mathrm{~A}$ & 0,10 & 0,27 & 0,07 & 39,10 & $2,13 \mathrm{~A}$ & 0,38 & 5,60 & 2,45 & 115,22 \\
\hline Magnésio & $0,14 \mathrm{~A}$ & 0,07 & 0,23 & 0,07 & 47,74 & $2,76 \mathrm{~A}$ & 0,35 & 7,70 & 3,44 & 124,66 \\
\hline Cálcio & $2,17 \mathrm{~A}$ & 1,02 & 3,44 & 1,01 & 46,45 & $21,55 \mathrm{~A}$ & 3,98 & 3,98 & 24,2 & 112,46 \\
\hline
\end{tabular}

Em uma mesma safra, valores médios de um mesmo nutriente seguidos de mesma letra maiúscula nấo diferem entre si pelo teste de Tukey (p>0,05). s: desvio-padrấo. C.V.: coeficiente de variação. Tratamentos: SD: sistema plantio direto. PC: sistema convencional com grade aradora.

Tabela 7. Estatísticas descritivas dos custos de reposição de nutrientes perdidos por erosão para o Ensaio Anterior (1990-1996)

\begin{tabular}{|c|c|c|c|c|c|c|}
\hline \multirow{2}{*}{ Tratamento } & \multirow{2}{*}{ Descrição } & Média & $\mathbf{s}$ & Mínimo & Máximo & CV \\
\hline & & \multicolumn{4}{|c|}{$\mathbf{R} \$ \mathrm{ha}^{-1}$} & $\%$ \\
\hline T1 & Grade aradora & $45,35 \mathrm{~A}$ & 12,22 & 35,70 & 68,25 & 26,95 \\
\hline $\mathrm{T} 2$ & Sistema Alternado & $44,40 \mathrm{~A}$ & 12,59 & 34,62 & 68,07 & 28,35 \\
\hline T3 & Escarificador & $44,33 \mathrm{~A}$ & 12,59 & 33,69 & 68,00 & 28,40 \\
\hline T4 & Plantio Direto & $41,40 \mathrm{~A}$ & 12,57 & 31,61 & 64,85 & 30,37 \\
\hline T5 & Aração em Nível & $44,88 \mathrm{~A}$ & 14,25 & 34,75 & 72,24 & 31,74 \\
\hline T6 & Roçado & $40,89 A$ & 12,91 & 30,86 & 65,01 & 31,57 \\
\hline $\mathrm{T7}$ & Aração Morro Abaixo & $63,92 \mathrm{~A}$ & 13,67 & 51,77 & 89,11 & 21,38 \\
\hline T8 & Rotavação & $50,97 \mathrm{~A}$ & 13,20 & 38,95 & 75,38 & 25,91 \\
\hline
\end{tabular}

Custos expressos em reais de 2005, computados os custos totais dos fertilizantes e das aplicaçốes. s: desvio-padrão. C.V.: Coeficiente de variaçấo.

Tabela 8. Estatísticas descritivas dos custos de reposição de nutrientes perdidos por erosão para duas safras do Ensaio Atual (2003-2005)

\begin{tabular}{|c|c|c|c|c|c|}
\hline \multicolumn{6}{|c|}{ Safra 2003/04 } \\
\hline Tratamento & Média & s & Mínimo & Máximo & C.V. \\
\hline Iratamento & \multicolumn{4}{|c|}{$R \$ h^{-1}$} & $\%$ \\
\hline SD & $63,35 \mathrm{~A}$ & 6,57 & 56,76 & 70,23 & 10,37 \\
\hline$P C$ & $129,79 \mathrm{~A}$ & 75,85 & 60,23 & 228,78 & 65,91 \\
\hline \multicolumn{6}{|c|}{ Safra 2004/05 } \\
\hline SD & $60,59 A$ & 4,21 & 55,95 & 66,12 & 6,95 \\
\hline$P C$ & $166,13 \mathrm{~A}$ & 133,17 & 69,15 & 352,46 & 80,15 \\
\hline
\end{tabular}

Custos expressos em reais de 2005, computados os custos totais dos fertilizantes e das aplicaçóes. s: desvio-padrăo. C.V.: Coeficiente de variaçáo. Tratamentos: SD: sistema plantio direto. PC: sistema convencional com grade aradora. 
torno de $74 \%$ dos custos anuais de reposição de nutrientes a partir da adoção do sistema plantio direto. Em termos médios não foram caracterizadas diferenças significativas entre tratamentos do Ensaio II. Entretanto, com relação a valores mínimos e máximos, as diferenças entre tratamentos são acentuadas, posto que os valores máximos ocorreram em parcelas manejadas sob sistema convencional (PC) para ambas as safras.

Em resumo, com relação ao sistema de manejo do solo, os resultados permitem reafirmar a manutenção da cobertura do solo e o plantio em nível como práticas essenciais ao controle da erosão em áreas agrícolas. A despeito de terem ocorrido diferenças significativas entre alguns tratamentos com relaçáo a perdas de solo e de nutrientes por erosão, não foi possível diferenciá-los em termos de produtividades e de custos de reposição de nutrientes. Presume-se que parte da explicação se relacione com a classe de solo em questão, um Latossolo Vermelho Distroférrico típico, profundo, argiloso, com estrutura forte granular que, sendo convenientemente adubado, consegue manter seu potencial produtivo ao longo do tempo, mesmo quando submetido a elevadas taxas de perda de solo. A esse respeito, em trabalho sobre erosão simulada e produtividade da cultura de milho em Argissolo Vermelho-Amarelo Distrófico latossólico, Sparover et al. (1991) relataram que as plantas bem adubadas se desenvolveram melhor em menor tempo, independentemente da profundidade de remoção de terra. Tais resultados indicam que o manejo com fertilizantes e corretivos, ao restaurar a fertilidade do solo, contribui para mascarar os efeitos da erosão sobre a produção de culturas. Com relação aos custos de reposição de nutrientes, em ensaios de longa duração, a variação anual de preços de fertilizantes e corretivos e de mão-de-obra também pode mascarar as diferenças devidas aos tratamentos em si. No caso particular do Ensaio II (atual), tendo-se analisado somente as duas safras iniciais, não se pode descartar uma possível influência de efeito residual dos tratamentos do Ensaio I (anterior) na qualidade do solo das parcelas experimentais, que pode ter mascarado os efeitos dos tratamentos do Ensaio II.

\section{CONCLUSÕES}

1. O método de valoração referido por custo de reposição se traduz em um critério objetivo para avaliação da sustentabilidade econômica de sistemas de manejo do solo quanto ao controle da erosão.

2. Em ensaios de longa duraçáo, comuns nas pesquisas em erosão do solo, o método pode ter como inconveniente ampla variação anual de preços de fertilizantes e corretivos e de mão-de-obra de sorte a mascarar os efeitos dos tratamentos em si.

\section{AGRADECIMENTOS}

Ao Instituto de Economia Agrícola, em especial aos pesquisadores Dr. ${ }^{a}$ Célia Murad, Dr. Benedito Freitas, Dr. ${ }^{a}$ Celma da Silva Lago Baptistella e Dr. Vagner Azarias Martins, pela cessão de dados e suporte técnico na definição das variáveis econômicas. Ao Dr. Bernardo van Raij, pelas sugestóes e comentários acerca do trabalho de pesquisa. À colega Laura Fernanda Simões da Silva, pela colaboração na realização das análises estatísticas.

\section{REFERÊNCIAS}

BLEVINS, R.L.; FRYE, W.W. Conservation tillage: an ecological approach to soil management. Advances in Agronomy, v.51, p.3378, 1993.

CASSOL, E.A.; LIMA, V.S de. Erosão em entressulcos sob diferentes tipos de preparo e manejo do solo. Pesquisa Agropecuária Brasileira, v.38, p.117-124, 2003.

CASTRO, O.M.; LOMBARDI NETO, F.; VIEIRA, S.R.; DECHEN, S.C.F. Sistemas convencionais e reduzidos de preparo do solo e as perdas por erosão. Revista Brasileira de Ciência do Solo, v.10, p.167-171, 1986.

DIXON, J.A.; HUFSCHMIDT, M.M. Economic Valuation for the Environment: A Case Study Workbook. Baltimore: The Johns Hopkins University Press, 1986. 203p.

ELTZ, F.L.F.; MEHL, H.U.; REICHERT, J.M. Perdas de solo e água em entressulcos em um Argissolo Vermelho-Amarelo submetido a quatro padróes de chuva. Revista Brasileira de Ciência do Solo, v.25, p.485-494, 2001.

GARDNER, K.; BARROWS, R. The impact of soil conservation investments on land prices. American Journal of Agricultural Economics, v.67, p.943-947, 1985.

HERTZLER, G.; IBANEZ-MEIER, C.A.; JOLLY, R.W. User costs of soil erosion and their effect on agricultural land prices: costate variables and capitalized Hamiltonians. American Journal of Agricultural Economics, v.67, p.948-953, 1985.

HUFSCHMIDT, M.M.; JAMES, E.; MEISTER, A.D.; BOWER, B.T.; DIXON, J.A. Environment, Natural Systems and Development: An Economic Valuation Guide. Baltimore: The Johns Hopkins University Press, 1983. 338p.

KING, D.A.; SINDEN, J.A. Influence of soil conservation on farm land values. Land Economics, v.64, p.242-55, 1988.

KITAMURA, P.C.; LANZER, E.A.; ADAMS, R.I. Avaliação econômica de sistemas conservacionistas no uso de solos agrícolas: o caso do binômio trigo-soja no Rio Grande do Sul. Revista de Economia e Sociologia Rural, v.20, p.104-124, 1982.

KOOTEN, G.C.; WEISENSEL, W.P.; CHILANTHAMMIT, D. Valuing trade-offs between net returns and stewardship practices: the case of soil conservation in Saskatchewan. American Journal of Agricultural Economics, v.72, p.104-113, 1990. 
LAL, R. Soil erosion and land degradation: the global risks. Advances in Soil Science, v.11, p.129-172, 1990.

MARQUES, J.F. Custos da erosão do solo em razão dos seus efeitos internos e externos à área de produção agrícola. Revista de Economia e Sociologia Rural, v.36, p.61-79, 1998.

MELO FILHO, J.F.; SILVA, J.R.C. Erosão, teor de água no Solo e produtividade do milho em plantio direto e preparo convencional de um Podzólico Vermelho-Amarelo no Ceará. Revista Brasileira de Ciência do Solo, v.17, p.291-297, 1993.

MUTCHLER, C.K.; MURPHREE, C.E.; McGREGOR, K.C. Laboratory and field plots for erosion research. In: LAL, R. Soil Erosion Research Methods. 2.ed. Delray Beach: St. Lucie Press, Soil and Water Conservation Society, 1994. p.1-9.

PIEARCE, F.J.; DOWDY, R.H.; LARSON, W.E.; GRAHAM, W.A.P. Soil productivity in the Corn Belt: an assessment of erosion's long-terms effects. Journal of Soil and Water Conservation, v.39, p.131-136, 1984.

PIERCE, F.J.; LAL, R. Monitoring the Impact of Soil Erosion on Crop Productivity. In: LAL, R. (Ed.) Soil Erosion Research Methods. 2.ed. Delray Beach, FL, St. Lucie Press, Soil and Water Conservation Service, 1994. p.235-63.

POPE, C. A. III, BHIDES, S.; HEADY, E. O. Economics of conservation tillage in Iowa. Journal of Soil and Water Conservation, v.38, p.370-373, 1983.
RAMALHO, M.A.P., FERREIRA, D.F., OLIVEIRA, A.C. Experimentação em genética e melhoramento de plantas. Lavras : UFLA, 2000. 326p.

RODRIGUES, W. Valoração econômica dos impactos ambientais de tecnologias de plantio em região de Cerrados. Revista de Economia e Sociologia Rural, v. 43, p. 135-153, 2005.

SPAROVEK, G.; TERAMOTO, E.R.; TORETA, D.M.; ROCHELE, T.C.P.; SHAYER, E.P.M. Erosão simulada e a produtividade da cultura do milho. Revista Brasileira de Ciência do Solo, v.15, p.363-368, 1991.

SWANSON, E.R.; MACCALLUM, D.E. Income effects of rainfall erosion control. Journal of Soil and Water Conservation, v.24, p.56-59, 1969.

THOMÉ JUNIOR, J.B. Manual para Interpretação de Análise de Solo. Guaíba: Livraria e Editora Agropecuária, 1997. 247p.

$\mathrm{XU}, \mathrm{F}$; PRATO, T. On site erosion damages in Missouri corn production. Journal of Soil and Water Conservation, v.50, p.312316, 1995.

WANG, X. B.; CAI, D. X.; HOOGMED, W. B.; OENEMA, O.; PERDOK, U. D. Potential effect of Conservation Tillage on Sustainable Land Use: A Review of Global Long-Term Studies. Pedosphere, v. 16, p.587-595, 2006. 